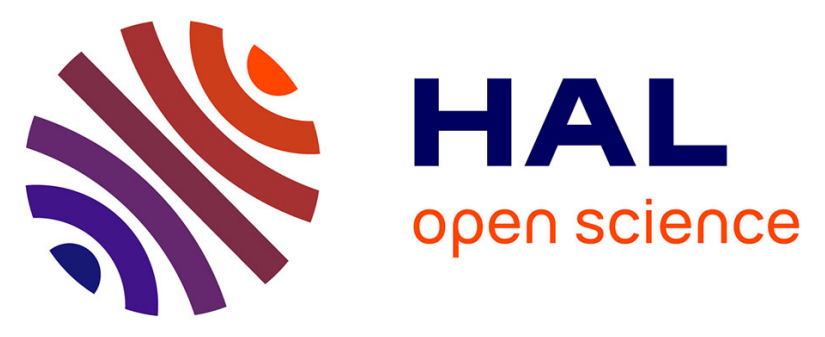

\title{
Experimental Investigation on Heat Transfer Enhancements in Laminar Flow with Ferrofluids - Application to Power Electronics Cooling
}

Wahid Cherief, Cong-Martin Wu, Yvan Avenas, Sébastien Ferrouillat, Laurent Jossic, Afef Kedous-Lebouc, Jean Bérard, Mickaël Petit

\section{To cite this version:}

Wahid Cherief, Cong-Martin Wu, Yvan Avenas, Sébastien Ferrouillat, Laurent Jossic, et al.. Experimental Investigation on Heat Transfer Enhancements in Laminar Flow with Ferrofluids - Application to Power Electronics Cooling. 20th International Workshop (Therminic 2014). Thermal investigations of IC'S and systems, Sep 2014, Londres, United Kingdom. 10.1109/THERMINIC.2014.6972499 . hal-01069580

\section{HAL Id: hal-01069580 \\ https://hal.science/hal-01069580}

Submitted on 10 Feb 2022

HAL is a multi-disciplinary open access archive for the deposit and dissemination of scientific research documents, whether they are published or not. The documents may come from teaching and research institutions in France or abroad, or from public or private research centers.
L'archive ouverte pluridisciplinaire HAL, est destinée au dépôt et à la diffusion de documents scientifiques de niveau recherche, publiés ou non, émanant des établissements d'enseignement et de recherche français ou étrangers, des laboratoires publics ou privés.

\section{(ㅇ)(1) $\$$}

Distributed under a Creative Commons Attribution - NonCommerciall 4.0 International 


\title{
Experimental Investigation on Heat Transfer Enhancements in Laminar Flow with Ferrofluids - Application to Power Electronics Cooling
}

\author{
Wahid Cherief ${ }^{1,2,3}$, Martin Wu ${ }^{1}$, Yvan Avenas ${ }^{* 1}$, Sébastien Ferrouillat ${ }^{2}$, Laurent Jossic ${ }^{3}$, Afef Lebouc ${ }^{1}$, Jean Berard ${ }^{1}$, Mickael \\ Petit $^{4}$. \\ ${ }^{1}$ Univ. Grenoble Alpes, G2Elab, F-38000 Grenoble, France. CNRS, G2Elab, F-38000 Grenoble, France. \\ ${ }^{2}$ Univ. Grenoble Alpes, LEGI, F-38000 Grenoble, France. CNRS, LEGI, F-38000 Grenoble, France. \\ ${ }^{3}$ Univ. Grenoble Alpes, LRP, F-38000 Grenoble, France. CNRS, LRP, F-38000 Grenoble, France. \\ ${ }^{4}$ SATIE, ENS Cachan - CNAM - Université de Cergy Pontoise - CNRS UMR 8029, 94230 Cachan. \\ * Corresponding Author: Yvan.Avenas@g2elab.grenoble-inp.fr, +33 47682 64 46, Grenoble, France.
}

\begin{abstract}
This paper presents an experimental investigation on forced convective heat transfers in a ferrofluid with the presence of a magnetic field. The duct is square, the flow is laminar and the wall heat flux is uniform. The effects of the direction of the magnetic field and of the thermal entrance region are studied. The results show that a better enhancement is made when the magnetic field and the heat flux are perpendicular. Moreover, the effect of the magnetic field seems to be more interesting for a fully developed flow. In the end of the paper, the thermal characterization of a 3D power electronics module cooled by the same ferrofluid is carried out.
\end{abstract}

\section{Introduction}

In recent years the field of power electronics has made considerable technological progress. However, several factors limit this progress, in particular those related to the thermal management of power semiconductor devices. In fact, the heat flux density can reach several hundred W.cm ${ }^{-2}$ in these components. For such thermal stresses, liquid cooling is frequently used. The relatively low thermal conductivity and specific heat capacity of the coolant fluid can limit the thermal performances of the system. In this context, during the two last decades, researchers have shown that nanofluids and ferrofluids could be used to enhance the convective heat transfers. These fluids are thus considered as excellent candidates for future cooling systems. Ferrofluids are stable colloidal dispersions of nano-sized ferromagnetic particles in a carrier liquid. A wide range of carrier liquids have been employed such as kerosene, water or oil. When a ferrofluid is placed into a magnetic field, a magnetostatic attraction appears between the nanoparticles. Furthermore, the Van der Waals forces are attractive if the distance between nanoparticles is short and become strong when the particles diameters are large enough. These two forces lead to an agglomeration of the particles and consequently to their sedimentation. In order to ensure the homogeneity and the stability of ferrofluids, the magnetic particles have a diameter which is generally close to $10 \mathrm{~nm}$ and are coated by a surfactant.

Several papers deal about the thermal conductivity in ferrofluids and their mechanism of enhancement since 2006. Philip et al. [1] explain that the mechanism of enhancement is attributed to the effective conduction of the heat flux through a chainlike structures formed in the ferrofluid. Indeed, the nanoparticles tend to align their magnetic moments with the direction of the magnetic field. Therefore, the thermal resistance of the ferrofluid decreases when the heat flux is oriented in the same direction than the magnetic field. Gavili et al. [2], measure the thermal conductivity of a ferrofluid containing $5 \%$ (volume fraction) of $\mathrm{Fe}_{3} \mathrm{O}_{4}$ nanoparticles suspended in water. A $200 \%$ increase is measured (the heat flux is also in the same direction than the magnetic field). Finally, the effect of the direction of the magnetic field on the thermal conductivity of ferrofluids is studied by Shima and Philip [3]. The authors show that the thermal conductivity is increased in the direction which is parallel to the magnetic field but it is not modified in the perpendicular direction. This effect seems to confirm that the enhancement of the thermal conductivity is due to the formation of particle chains.

Few experimental investigations about the forced convective heat transfer coefficient in ferrofluids were carried out. However, they tend to make them eligible as future coolants. Lajavardi et al. [4] conclude that the increase of the volume fraction and the magnetic field intensity are possible factors of enhancing the specific heat and the thermal conductivity of ferrofluids. Thus, convective heat transfers are better (50\% improvement compared to the carrier fluid under $0.12 \mathrm{~T})$. Azizian et al. [5] through an experimental investigation using a $\mathrm{Fe}_{3} \mathrm{O}_{4} / \mathrm{Di}$-water suspension at a volume fraction of $0.86 \%$ show that in a laminar flow, the convective heat transfer coefficient can be $300 \%$ enhanced under magnetic field $(0.43 \mathrm{~T})$. Motozawa et al. [6] investigate experimentally the heat transfer performance of a $\mathrm{Fe}_{3} \mathrm{O}_{4} /$ water ferrofluid flowing through a rectangular duct in a laminar or turbulent flow. The heat flux is imposed on only one wall, the others being insulated from the outside environment. The results demonstrate a $40 \%$ increase of the convective heat transfer coefficient in laminar flow under 
magnetic field. In turbulent flow, no improvement is observed.

Due the relatively low number of papers dealing with this topic, the behaviour of the convective heat transfer coefficient under magnetic field and the reason of its enhancement are today not clear. Some explanations are given by the authors:

- [4-5] assume that the enhancement of the convective heat transfer coefficient is due to the interaction and accumulation of nanoparticles which induce the formation of particle chains as it is the case for the thermal conductivity.

- Motozawa et al. [6] show with a dedicated experimental setup that the enhancing is due to a deformation of the streamlines of the velocity field under the action of the magnetic field. Indeed, the velocity gradient at the wall is considerably increased which allows improving the convective heat transfer.

From this literature review, it can be concluded that more intense researches have to be carried out to better understand the physical phenomena which occur in ferrofluids under magnetic field. This is why, in the first part of this paper, we propose an original experimental setup to evaluate the convective heat transfer coefficient in different configurations of the magnetic field. A focus will be made on the effect of the direction of the magnetic field: it can be parallel or perpendicular to the direction of the heat flux. These both configurations, based on the use of a square channel, will help us to have a better understanding of the physical phenomena in ferrofluids. Moreover, in lots of finned cooling systems in electronics, the channels have a rectangular or a square shape. Hence, it is important to know with a good accuracy the evolution of the heat transfer coefficient as a function of the orientation of the magnetic field.

In the final section of the paper, the experimental setup will be modified to characterize the thermal resistance of a $3 \mathrm{D}$ power electronics module which is cooled by a ferrofluid flow.

\section{Basic principles of the thermo-hydraulic characterization}

\subsection{Experimental Setup}

Heat transfer enhancement in ferrofluids under magnetic field is studied through an experimental setup based on a closed loop flow system (figure 1). It mainly consists of a tank, a gear pump, a heat exchanger, a flow meter (DOM$\mathrm{x} 10$, accuracy $\pm 1 \%$ ), 2 pressure transducers (Keller-33X, accuracy $\pm 0.1 \mathrm{kPa})$, a test section and magnetic sources. The test section is composed of two copper plates of $1.5 \mathrm{~m}$ length separated by an insulating material plate. In the latter, a groove of $4 \mathrm{~mm} * 4 \mathrm{~mm}$ is machined (figure 2). To generate a constant and uniform heat flux, electrical film resistors are mounted on the copper plates. The length of each resistor is
$1 \mathrm{~m}$ and the width is $4 \mathrm{~mm}$. It has to be noted that the length of the resistor is lower than the length of the copper plates. In fact, a $0.5 \mathrm{~m}$ free length is used at the entrance of the test section to have a hydrodynamically fully developed flow when the ferrofluid enters in the heated region.

Two K-type thermocouples are inserted in the fluid to measure the inlet and outlet temperatures of the test section. Ten K-type thermocouples are installed in the copper plates (figure 1). The distance between each thermocouple is 100 $\mathrm{mm}$. The accuracy of the temperature measurements is evaluated to be $0.3^{\circ} \mathrm{C}$.

In order to minimize the volume of ferrofluid, the pressure drop in the test section is determined by two absolute pressure sensors installed before and after the resistors.

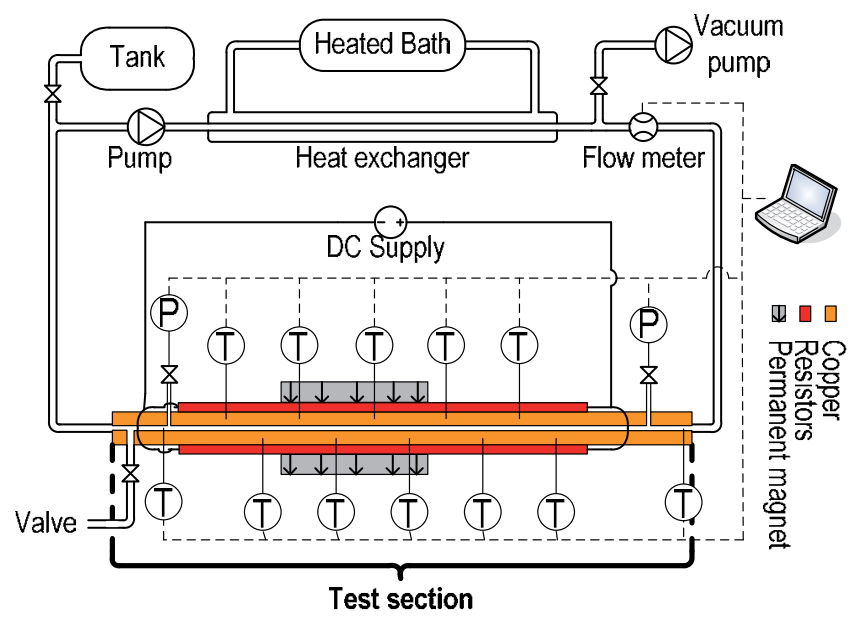

Figure 1: Experimental setup

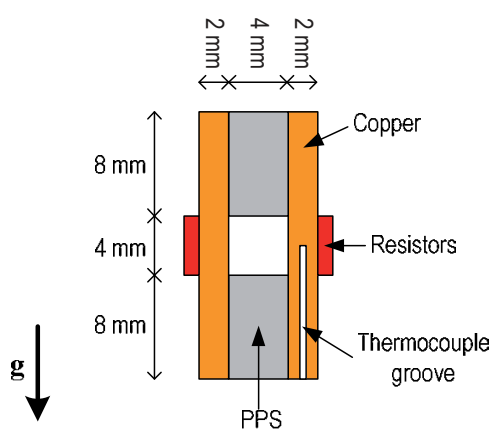

Figure 2: Cross section of the test section

A magnetic field is applied along the test section. This field is generated by several elementary magnetic sources. Each magnetic source is constituted by a magnetic yoke including $\mathrm{NdFeB}$ permanent magnets (figure 3.a). Figure 3.b shows the mapping of the magnetic flux density in the $34 \mathrm{~mm}$ air gap of a magnetic source obtained by numerical simulations. The magnetic flux density value in the center of the air gap is $0.57 \mathrm{~T}$. Figure 4 presents the y component of the magnetic flux density along $\mathrm{C} 1$ and $\mathrm{C} 2$ lines (figure 3.b). Thus, we conclude that the magnetic flux density is quasi uniform in the effective area (the section of the duct when it is placed in the center of the air gap). In order to validate simulations, the magnetic flux density was measured with an accurate 
Tesla meter (Magnet-Physik FH51 gauss meter). The magnetic flux density was evaluated to be $0.54 \mathrm{~T}$ (difference close to $5.5 \%$ with simulations) and its uniformity was validated in the effective area.

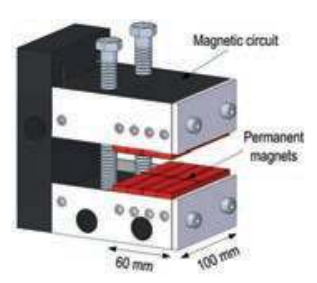

(a) (b)

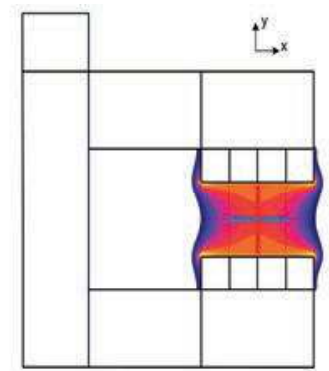

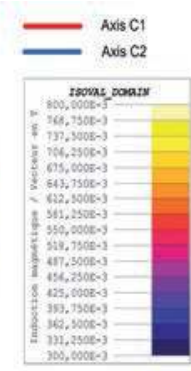

Figure 3: The magnetic sources (a) dimensions, (b) mapping of magnetic flux density in air gap of $34 \mathrm{~mm}$.

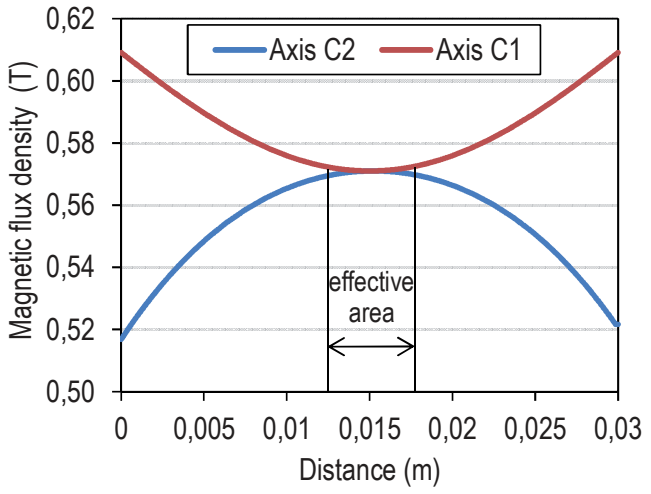

Figure 4: Y component of the magnetic flux density in the air gap

\subsection{Experimental parameters}

The ferrofluid (EFH-1) used in this studies was purchased from Ferrotec. It is a stable colloidal of $\mathrm{Fe}_{3} \mathrm{O}_{4}$ nanoparticles suspended in a mineral oil. The volume fraction of $\mathrm{Fe}_{3} \mathrm{O}_{4}$ is $7.3 \%$. Physical properties of EFH-1 are given in table 1 . The viscosity and specific heat of the ferrofluid were also measured (without magnetic field) by a Couette viscometer and a calorimeter respectively. The results are shown in figure 5 . We observe that the variation of the viscosity is very large in all the temperature range. We consider our measures to calculate the Reynolds number.

Table 1: Physicals properties of EFH-1(Ferrotec source).

\begin{tabular}{|c|c|c|c|c|}
\cline { 2 - 5 } \multicolumn{1}{c|}{} & $\begin{array}{c}\boldsymbol{\rho} \\
\mathrm{kg} \cdot \mathrm{m}^{-3}\end{array}$ & $\begin{array}{c}\mathbf{C}_{\mathbf{p}} \\
\mathrm{J} \cdot \mathrm{kg}^{-1} \cdot \mathrm{K}^{-1}\end{array}$ & $\begin{array}{c}\mathbf{T} \\
{ }^{\circ} \mathrm{C}\end{array}$ & $\begin{array}{c}\boldsymbol{\mu} \\
\mathrm{mPa} . \mathrm{s}\end{array}$ \\
\hline Mineral oil & 920 & 1670 & 20 & - \\
\hline $\begin{array}{c}\text { Magnetite } \\
\left(\mathbf{F e}_{3} \mathbf{O}_{\mathbf{4}}\right)\end{array}$ & 5180 & 670 & 20 & - \\
\hline Ferrofluid & 1210 & - & 20 & 6 \\
\hline
\end{tabular}

The magnetic field source has a total length of $400 \mathrm{~mm}$. This means that only four magnetic circuits (Figure 3.a) are used. This configuration will allow us to observe the effect of the magnetic field on the convective heat transfer coefficient in the thermal entrance and in the thermally developed regions. The characterization of the ferrofluid is made in laminar flow for 5 configurations: 1) without magnetic field; 2) with magnetic field parallel to the heat flux in the thermally developed region; 3) with magnetic field perpendicular to the heat flux in the thermally developed region; 4) with magnetic field parallel to the heat flux in the thermal entrance region; 5) with magnetic field perpendicular to the heat flux in the thermal entrance region. For this study the electrical resistors apply a power density of $2.5 \mathrm{~W} . \mathrm{cm}^{-2}$ in the test section.

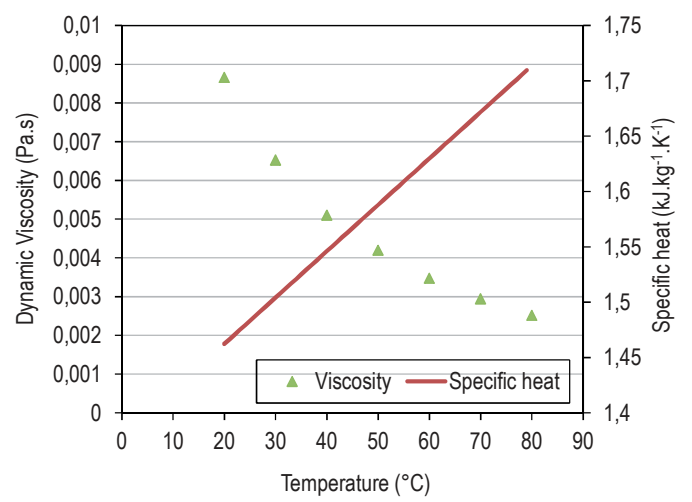

Figure 5: Specific heat and viscosity of EFH-1 without magnetic field

\subsection{Data analysis}

Assuming that the heat flux density is uniform, the local convective heat transfer coefficient, $\mathrm{h}(\mathrm{x})$, is calculated based on the energy balance in the test section as follows:

$$
h(x)=\frac{P}{S\left(T_{w}(x)-T_{f}(x)\right)}
$$

where $T_{w}$ and $T_{f}$ are the wall and bulk fluid temperatures, $x$ the axial distance from the thermal entrance of the test section $(\mathrm{m}), S$ the surface exchange $\left(\mathrm{m}^{2}\right)$ and $P$ the thermal power received by the fluid $(\mathrm{W})$ which is obtained by:

$$
P=Q_{m} C_{p}\left(T_{s}-T_{e}\right)
$$

where $Q_{m}$ is the mass flow rate $\left(\mathrm{kg} . \mathrm{s}^{-1}\right), C_{p}$ the specific heat $\left(\mathrm{J} \cdot \mathrm{kg}^{-1} \cdot \mathrm{K}^{-1}\right), T_{s}$ and $T_{e}$ respectively the inlet and outlet bulk fluid temperatures. In (1), $T_{f}(x)$ is obtained through the energy balance defined as ( $\mathrm{L}$ is the length of heated part of the test section):

$$
T_{f}(x)=\frac{P}{L Q_{m} C_{p}} x+T_{e}
$$

\section{Results and discussion}

\subsection{Pressure drops}

Pressure drops measurements with different Reynolds numbers at $20^{\circ} \mathrm{C}$ are first presented. Three tests were made with respect to the procedure described in paragraph 2.2. The results are regrouped in figure 6 . The test without magnetic field is compared with a Darcy's correlation for a square duct [7]. There is a good agreement between 
measurements and theoretical results. When the magnetic field is applied, an increase of the pressure drops up to $20 \%$ $( \pm 3 \%)$ is observed. However, the orientation of the magnetic field has not any impact on the pressure drops, which confirms the symmetry of our system. Thus, the energy required to set in motion the ferrofluid is identical in the parallel and perpendicular cases.

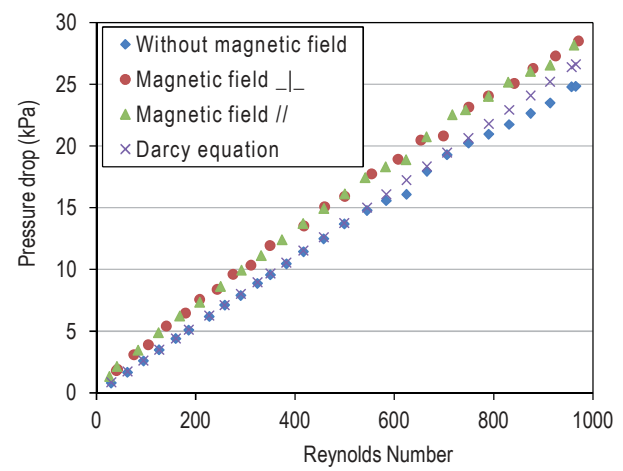

Figure 6: Pressure drops at different Reynolds numbers

\subsection{Influence of the magnetic field direction}

Heat transfer characterizations are presented for different Reynolds numbers in laminar flow in this paragraph. Before carrying out the main investigation, the influence of the magnetic field on the thermocouple measurements was evaluated. Several tests using water as coolant fluid with and without magnetic field were conducted. Results show that the temperature measurements remain identical in both cases. Therefore, the thermocouples measurements are not affected by the magnetic field.

Figure 7 represents the evolution of the local convective heat transfer coefficient $h$ versus the position of the thermocouples in the test section. Three configuration are tested: without magnetic flux, with a magnetic field parallel to the heat flux in the thermally developed region and with a magnetic field perpendicular to the heat flux in the thermally developed region. This configuration of magnetic field is called "Magnetic field 1" in the figures.

It can be inferred that the magnetic field leads to a large improvement of the local convective heat transfer coefficient. When the magnetic field is perpendicular to the heat flux, the enhancement of $\mathrm{h}$ reached $80 \%$ compared to the case without magnetic field. With the parallel magnetic field, the $\mathrm{h}$ improvement is only $40 \%$.

It should be noted that, in all cases, the two last measurement points show an increase of the local heat transfer coefficient. In fact, this is the result of a thermal dissipation at the end of the test section through the copper plates. As a consequence, the heat flux density is lower in this area which induces an overestimation of the $h$ value.

The hydraulic studies on the orientation of the magnetic field show that the pressure drops remain unchanged in the parallel and perpendicular cases. However, the thermal investigations indicate a difference of $40 \%$ between both configurations. If the enhancement of heat transfers under magnetic field was due to the chainlike structures as explained in [4-5], the configuration with a parallel field should give better results than the perpendicular case.

In addition, in another study, we have already evaluated the thermal conductivity of EFH-1. As [3], we concluded that the thermal conductivity is higher in the direction of the magnetic field. In fact a $25 \%$ enhancement (for $30^{\circ} \mathrm{C}$ ) was observed with the parallel configuration. But, in the perpendicular case, no considerable enhancement was observed. Consequently, the improvement of the local heat transfer coefficient is probably related to the local deformation of the streamlines of the velocity field under the action of the magnetic field.

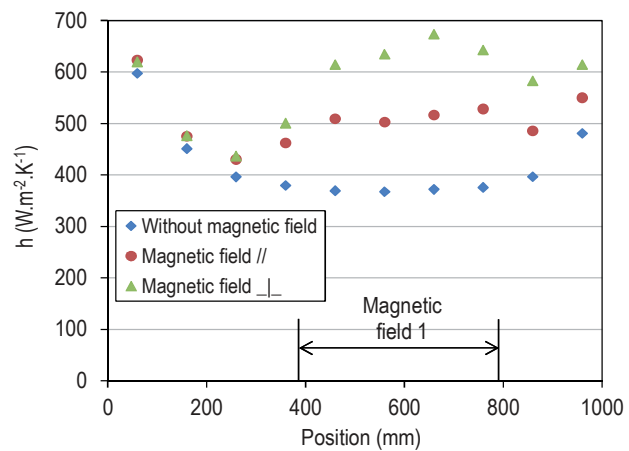

Figure 7: Local convective heat coefficient for Re=177 with magnetic field 1

\subsection{Influence of the Reynolds number}

Figure 8 shows that the convective heat coefficient is more influenced by the magnetic field for low Reynolds numbers. Indeed, when $\operatorname{Re}=575$, the enhancement of $\mathrm{h}$ is respectively about $27 \%$ and $54 \%$ for the parallel and perpendicular magnetic fields. This result is in concordance with the work of Motozawa [6]. For fully turbulent flows ( $\operatorname{Re}>2300)$, the flow controls the majority of heat transfer, making thus the intensification of heat transfer through the use of ferrofluids under magnetic field less efficient.

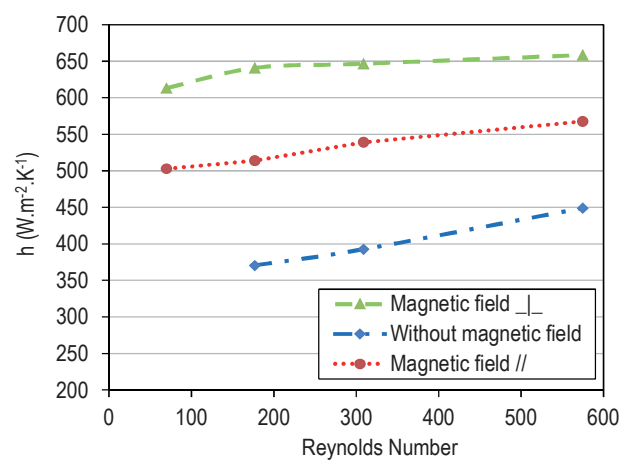

Figure 8: Variation of the average convective heat transfer coefficient with the Reynolds number (magnetic field 1)

\subsection{Influence of the thermal entrance region}

This paragraph presents the measurements of the local heat transfer coefficient with a magnetic source located in the thermal entrance region. The magnetic source is called 
"magnetic source $2 "$ in the figures. Figure 9 shows that the enhancement of the heat transfer coefficient is less important than in the previous configurations.

This affirmation is confirmed by figure 10. In fact, this figure shows the comparison between the local convective heat coefficients in "magnetic field 1" and "magnetic field 2" configurations for two Reynolds numbers. It can be seen that the remarkable enhancement is achieved in the thermally developed region. Indeed, the average enhancement for the perpendicular case in the thermally developed region is $40 \%$ higher than the average enhancement for the perpendicular case in the thermal entrance region. Several research works about ferrofluid [48] are performed in the case of developing region. Therefore, for real applications, it is more interesting to install the magnetic field source in the region where the flow is thermally developed.

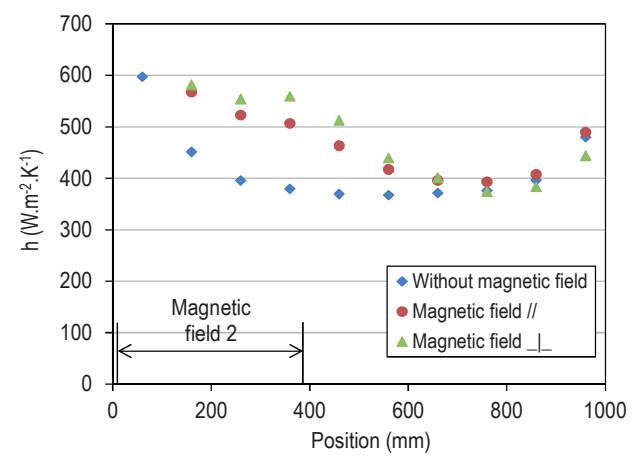

Figure 9: Local convective heat coefficient for Re=177 with magnetic field 2 located in thermally developing flow

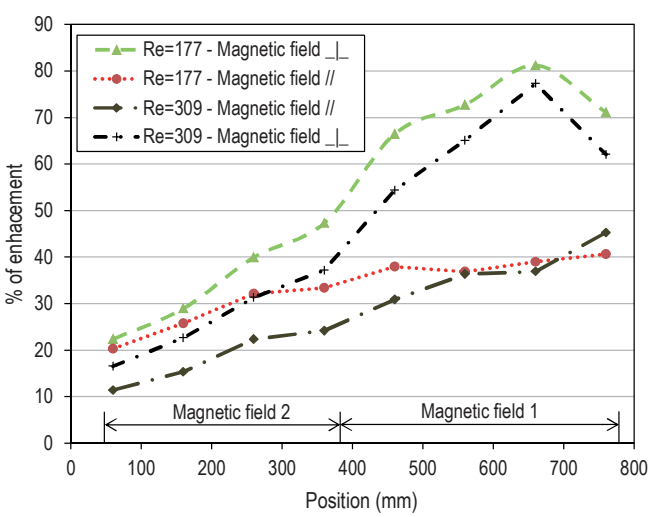

Figure 10: Influence of the magnetic field location: \% of enhancement $=[h$ (with magnet) $-h$ (without magnet) $] / h$ (without magnet)

Finally, it has to be noted that figure 9 shows that, when the ferrofluid flow leaves the region under magnetic field, the convective heat transfers remain better compared to the case without magnetic field. This could be advantageous to benefit from this phenomenon in specific applications.

\section{Thermal characterization of a power module}

This section describes the thermal characterization of a $3 \mathrm{D}$ power module. The interest of this study is to observe the thermal behavior of a ferrofluid in a real application.

\subsection{Experimental setup}

The characterized device is a double sided 3D power module without any bondwire. It is constituted by two power diodes and two insulated gate bipolar transistors (IGBT) (figure 11). The test section (figure 1) was replaced by this device.

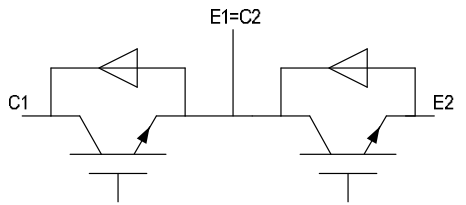

Figure 11: Electrical schematic of power module

Figure 12 presents a schematic section of the device and its direct cooling circuit. As shown in this figure, the liquid flow is directly integrated in the power module. Both sides of the semiconductor dies are cooled. Each cooling channel has a rectangular section $(26 \mathrm{~mm}$ in width and $0.5 \mathrm{~mm}$ in height). The length of the channels is $57.3 \mathrm{~mm}$. In this paper, only diode 1 is characterized. The aim of this study is to measure the thermal resistance of diode 1 as a function of the flow rate for two configurations: with and without magnetic field. Due to the sizes of the power module and of the magnetic field sources, it is impossible to have the magnetic field perpendicular to the heat flux. Therefore, only the parallel configuration is studied.

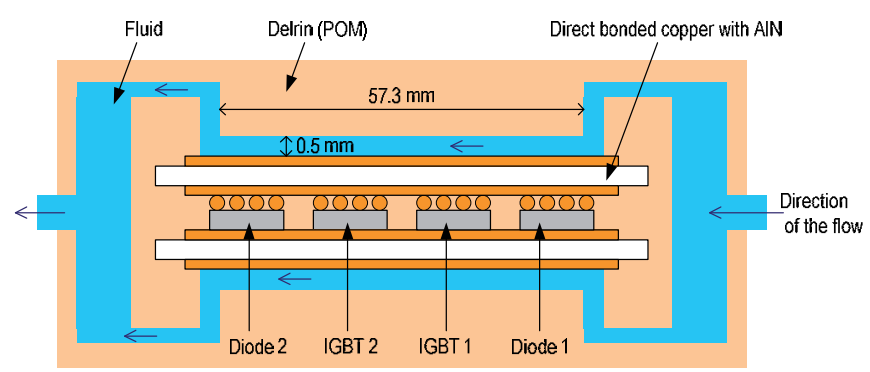

Figure 12: Schematic cross section of the power module

The thermal resistance of the diode is defined as:

$$
R_{t h}=\frac{T_{j}-T_{e}}{P}
$$

where $P$ is the injected power in diode $1, T_{j}$ and $T_{e}$ are the junction and the inlet bulk fluid temperatures.

$T_{e}$ is measured with a thermocouple located at the inlet of the power module. The junction temperature of diode 1 is measured using a classical thermo-sensitive electrical parameter: the forward voltage under a low current [9].

\subsection{Results and discussion}

Experiments were carried out with different mass flow rates $\left(4 \mathrm{~kg} \cdot \mathrm{h}^{-1}<\mathrm{Q}_{\mathrm{m}}<95 \mathrm{~kg} \cdot \mathrm{h}^{-1}\right)$. The injected power is $100 \mathrm{~W}$ and 
the inlet temperature of the ferrofluid is $T_{e}=20^{\circ} \mathrm{C}$. The applied magnetic field intensity is $0.51 \mathrm{~T}$ for a $38 \mathrm{~mm}$ air gap. The results are given in figure 13 .

Contrarily to results showed in the previous sections, figure 13 indicates that applying the magnetic field induces an increase of the thermal resistance. Specifically, the junction temperature measurement remains almost unchanged for low masse flow rates and the difference between each configuration rises with the flow rate. The possible reasons (hypothesis) of this behaviour are numerous. First, the ferrofluid could interact with the magnetic field gradient according to the Kelvin force equation, thus, the nanoparticles could migrate to the plastic wall. Consequently, the region near diode 1 could be depleted of nanoparticles. Secondly, diode 1 is situated in the region where the flow is not hydrodynamically and thermally developed. We have already seen that better enhancements of heat exchanges are obtained when the thermal profile is established. So, it could be interesting to check the effect of the hydrodynamic behavior on the enhancement of heat transfers. Finally, it could be possible that our ferrofluid was agglomerated. The nanoparticles would not be in suspension; therefore, the heat transfers would not be enhanced.

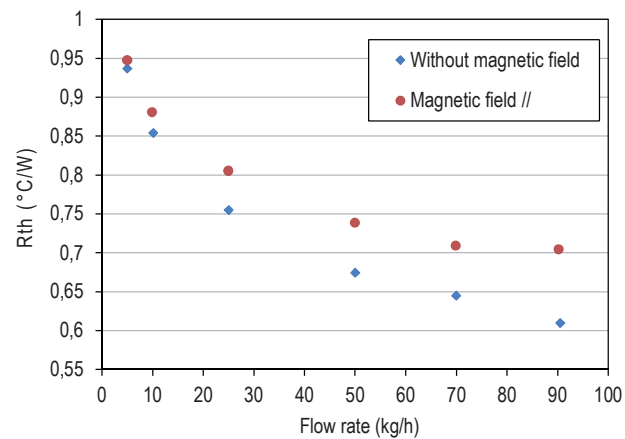

Figure 13: Thermal resistance of diode 1

\section{Conclusion and perspectives}

An enhancement of convective heat transfers by using a ferrofluid under magnetic fields is demonstrated:

- A better enhancement is measured when the magnetic field is perpendicular to the direction of the heat flux,

- At the outlet of the region under the magnetic field, heat transfers remain enhanced,

- The magnetic field applied in the region where the flow is thermally developed leads to the best improvement of the convective heat transfer coefficient,

- An increase of the Reynolds number under magnetic field, adversely affects the enhancement of the convective heat transfers.

However, the experiments with the power module showed that the junction temperature can increase when applying a magnetic field. In future works, others investigations will be made with $2 \mathrm{D}$ power module and with different volume fractions of nanoparticles. The geometries must take account the establishment of velocity and temperature profile in order to make a comparison with the entrance region. The electrical behaviour of power devices has also to be studied especially during the switching on and switching off.

Finally, note that the generalization of the results presented in this paper is not obvious. This study was performed with one kind of ferrofluid. In the future we will therefore test different fluids (other nanoparticles and carrier fluids) in different conditions (variation of the magnetic field intensity, alternating magnetic flux density) to check if physical phenomena are still valid.

\section{Acknowledgements}

This work has been supported by the Grenoble Institute of Technology through the Bonus Quality Research. The authors would like to thank the Schneider Electric company for their support regarding power module thermal characterization.

\section{Literature}

[1] J. Philip et al "Enhancement of thermal conductivity in magnetite based nanofluid due to chainlike structures", Applied Physics Letters, 91, 203108 (2007).

[2] A. Gavili, F. Zabihi, T. Dallali Isfahani, J. Sabbaghzadeh. "The thermal conductivity of water base ferrofluids under magnetic field" Exp. Thermal and Fluid Science, Vol. 41, pp. 94-98, Sept. 2012.

[3] P. D. Shima et J. Philip, "Tuning of Thermal Conductivity and Rheology of Nanofluids Using an External Stimulus", J. Phys. Chem. C, vol. 115, no 41, pp. 20097-20104, oct. 2011.

[4] Lajavardi et al., "Experimental investigation for enhanced ferrofluid heat transfer under magnetic field effect", Journal of Magnetism and Magnetic Materials, vol. 322, pp. 3508-3513, Issue 21, nov. 2010.

[5] J.R. Azizian et al., "Effect of magnetic field on laminar convective heat transfer of magnetite nanofluides", International Journal of Heat and Mass Transfer, vol. 68, pp. 94-109, Jan. 2014.

[6] M. Motozawa et al., "Variation of forced convective heat transfer in rectangular duct flow of a magnetic fluid under magnetic field", 13th Int. Conf. on Electrorheological Fluids and Magnetorheological Suspensions (ERMR2012). Turcland (2012).

[7] I.E. Idel'cik, "Mémento des pertes de charges", 3rd édition. Eyrolles, EDF, 1986.

[8] A. Ghofrani, M. H. Dibaei, A. Hakim Sima, et M. B. Shafii, "Experimental investigation on laminar forced convection heat transfer of ferrofluids under an alternating magnetic field", Exp. Therm. Fluid Sci., vol. 49, pp. 193-200, sept. 2013.

[9] Y. Avenas et L. Dupont, "Evaluation of IGBT thermosensitive electrical parameters under different dissipation conditions - Comparison with infrared measurements", Microelectron. Reliab., vol. 52, no 11, pp. 2617-2626, nov. 2012. 